\title{
Fiber Bragg Grating sensors for on-line welding diagnostics
}

\author{
L. Rodriguez-Cobo, J. Mirapeix, R. Ruiz-Lombera, A. Cobo and J.M. Lopez-Higuera \\ Universidad de Cantabria, Edificio I+D Teleco (Plaza de la Ciencia s/n), Santander, Spain;
}

\begin{abstract}
In this work Fiber Bragg Grating transducers (FBGs) are used to perform an on-line monitoring of an arc-welding process by means of the combined temperature and strain profile. The main goal of this approach is to establish a correlation between the appearance of defects in the seams and the response offered by the FBGs, exploring the optimal disposition of the FBGs in terms of their sensitivity to weld defects. The proposed solution will be explored by means of welding tests and a comparison with a plasma spectroscopic analysis.
\end{abstract}

Keywords: Optical Fiber, Bragg grating, welding, plasma spectroscopy

\section{INTRODUCTION}

Different techniques have been explored for on-line welding quality monitoring, from plasma spectroscopy ${ }^{12}$ to infrared thermography, ${ }^{3}$ machine vision ${ }^{4}$ or acoustic monitoring, ${ }^{5}$ also involving the employment of various processing techniques, such as artificial neural networks, ${ }^{6}$ fuzzy logic ${ }^{7}$ redundancy removal, ${ }^{6}$ feature selection ${ }^{8}$ or optimization algorithms, ${ }^{9}$ just to mention some examples. The complexity of the welding process (independently of the specific variety: arc, laser, plasma, etc.) and its widespread use in a wide variety of industrial processes justify this effort, given that an efficient real-time monitoring will imply a significant advantage in terms of productivity and, hopefully, of knowledge regarding the process.

Although different approaches have been analyzed, Fiber Bragg Grating transducers ${ }^{10}$ have been scarcely used in this regard, an only a few works deal with welding monitoring. Suarez et al. ${ }^{11}$ employed a FBG bonded on the bottom side of the welding plate to estimate both dynamic and residual stresses generated in the heat affected zone (HAZ) during the process. Moreira et al. ${ }^{12}$ also used FBGs in addition to thermocouples and thermography to obtain a temperature estimation in a gas metal arc welding (GMAW) process; while RichterTrummer et al. monitored both metal inert gas (MIG) and friction stir welding (FSW) processes using FBGs. ${ }^{13}$ In this latter work, the authors performed a detailed strain and temperature sensor calibration, showing FBG strain profiles for some experiments.

The works mentioned above do not exhibit results regarding the appearance of flaws during the process, what is a key point in terms of quality assurance in different industrial applications. ${ }^{14}$ FBGs allow to measure temperature or strain by finding the relation of these parameters to the measured displacement of the FBG Bragg wavelength. In our study, we have tried to find a correlation between some simulated weld flaws and perturbations in that wavelength, apart from the expected temperature evolution to be exhibited by the plates. Plasma spectra have also been captured during the welding tests to allow a comparison of the proposed solution with spectroscopic monitoring parameters. These results will be discussed in the following sections.

\section{EXPERIMENTAL SETUP}

In order to validate the proposed solution, several welding tests have been performed using a TIG (Tungsten Inert Gas) arc-welding system formed by a power source (Kemppi Mastertig 2200) and a welding torch (Kemppi TTC 220) controlled by a PC. Two plates (stainless steel AISI-304) are fastened to a base where backing gas (Argon, in addition to the protection gas coming from the torch) is provided to the bottom of the plates to prevent contamination. The seams are generated by the movement of the torch over the plates by means of a positioning system with a controller (Newport MM4005) and two linear stages (Newport MTM100PP1) with 1 um resolution. A photo of the welding system is depicted in Fig 1 (left).

Further author information: (Send correspondence to J. Mirapeix) E-mail: jesus.mirapeix@unican.es, Telephone: $(+34) 942206736$

Fifth European Workshop on Optical Fibre Sensors, edited by Leszek R. Jaroszewicz, Proc. of SPIE Vol. 8794, 879441 · C 2013 SPIE · CCC code: 0277-786X/13/\$18 · doi: 10.1117/12.2025723 

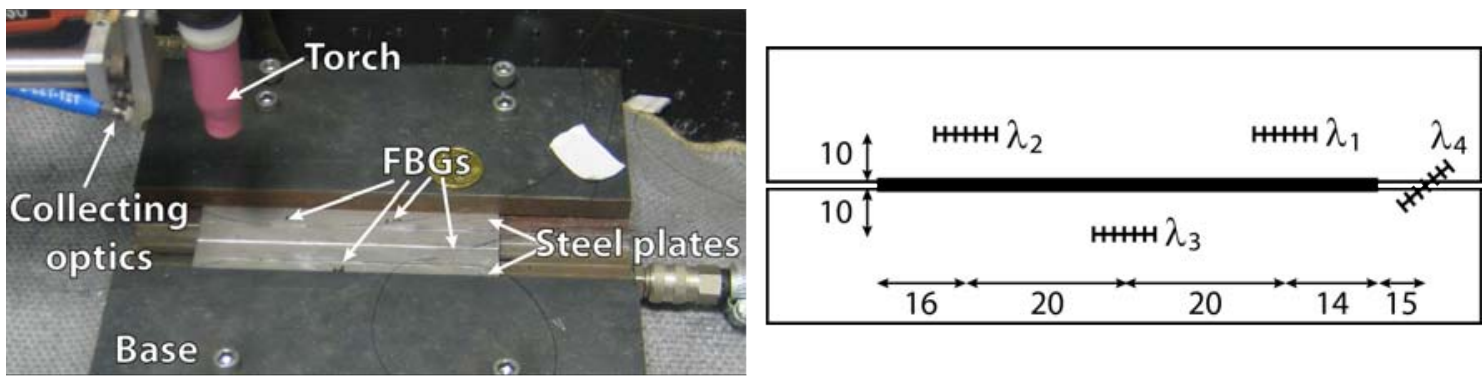

Figure 1. Photo of the employed welding setup (left) and schame of the FBGs location within the plates (right). Four FBGs are glued to the surface (top) of the welding plates surrounding the section to be welded. Dimensions are in millimeters.

After fastening the steel plates, four FBGs of $4 \mathrm{~mm}$ length were glued to the plates surfaces (top side) (Fig. 1, right). Three were located parallel to the joint (two in one plate and one in the other) and the fourth was glued over the welding joint. These FBGs were interrogated using a commercial unit (Micron Optics Si425-500) with a maximum sampling frequency of $250 \mathrm{~Hz}$. In addition to the FBGs, a plasma spectroscopy setup was also employed to collect and record the plasma optical radiation. The optical setup used in this regard was formed by two optical fibers (300 um core-width) and two CCD spectrometers (Ocean Optics HR400 and BWTEK Econic).

Maintaining the described setup, two different weld flaws have been simulated by changing some parameters like the welding current or support gas at preset locations. The FBGs measurements and the plasma radiation were recorded during the welds via $\mathrm{PC}$ to allow a comparison between both strategies in terms of weld flaw detection. In terms of the processing of the plasma spectra, a simple strategy based on the estimation of the plasma-RMS signal ${ }^{15}$ has been chosen, where the output monitoring parameter is proportional to the process heat input.

\section{RESULTS AND DISCUSSION}

Two seams of $L_{w}=70 \mathrm{~mm}$ have been performed using the same plates: in the first one, the two plates were just located edge to edge, thus allowing vibration between the plates to take place; in the second pass, the two plates were already welded, so there was no vibration between the edges. These conditions have been selected to allow the isolation of certain perturbations during the experiments. In the first seam, a welding current drop and an interruption of the support gas have been performed at $L_{1}=30 \mathrm{~mm}$ and $L_{2}=55 \mathrm{~mm}$ respectively. In the second pass, two support gas interruption have been performed at $L_{1}=20 \mathrm{~mm}$ and $L_{2}=40 \mathrm{~mm}$. All the perturbations have a duration length of $\Delta L=5 \mathrm{~mm}$. The data obtained from the first weld is depicted in Fig. 2

As the torch advances within the weld there is a temperature increase of each FBG creating positive wavelength drifts following the location order of the transducers (the first one is $\lambda_{2}$ ). Due to the welding process, a little bending can provoke a negative drift of certain FBGs (i.e. $\lambda_{3}$ ) but the thermal influence is bigger. In this pass (corresponding to a real weld) two perturbations have been introduced: a current drop $\left(T_{1} \approx 4 \mathrm{sec}\right)$ and an interruption of the support gas $\left(T_{2} \approx 7 \mathrm{sec}\right)$. The first perturbation is clearly detected by the RMS signal (there is a small drop and a sudden increase), but it is more complicated to be observed in the FBGs signals. However, the heat drop due to the reduction of the torch current can be appreciated in the thermal slope of the "heated" FBGs $\left(\lambda_{3}\right.$ and $\left.\lambda_{2}\right)$. While the welding process is working properly, the heating slope is approximately constant until a discontinuity is reached. However, this assumption is just valid when the FBG is within the heating ramp, when the maximum temperature is reached, there is no slope available to analyze. The second perturbation (support gas shortage) provokes a sudden vibration in the welding process that can be easily recognized both in the RMS and FBG signals (mainly in $\lambda_{1}$ and $\lambda_{4}$ ). Finally, when the process ends, there is a sudden change in the FBG placed between the two plates $\left(\lambda_{4}\right)$ that can be caused by a stress reduction in the welded plates. In order to isolate some effects of the welding process, another pass is performed over the two welded plates. In this pass, two the support gas interruptions have been performed to analyze the FBG response to non-vibrating conditions. Results are depicted in 3. 


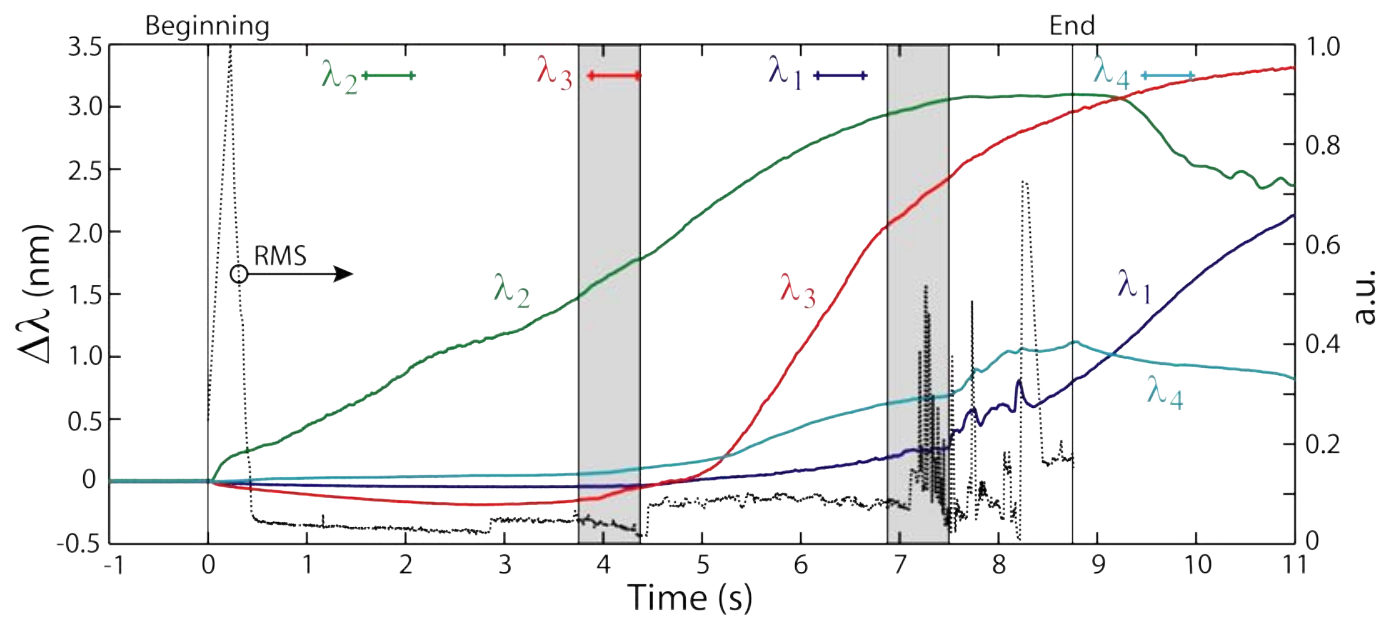

Figure 2. Data from the FBGs are depicted against the welding time (solid lines). The RMS processed optical radiation is also shown (dotted line). The equivalent FBG position and weld limits are also plotted over the time scale.

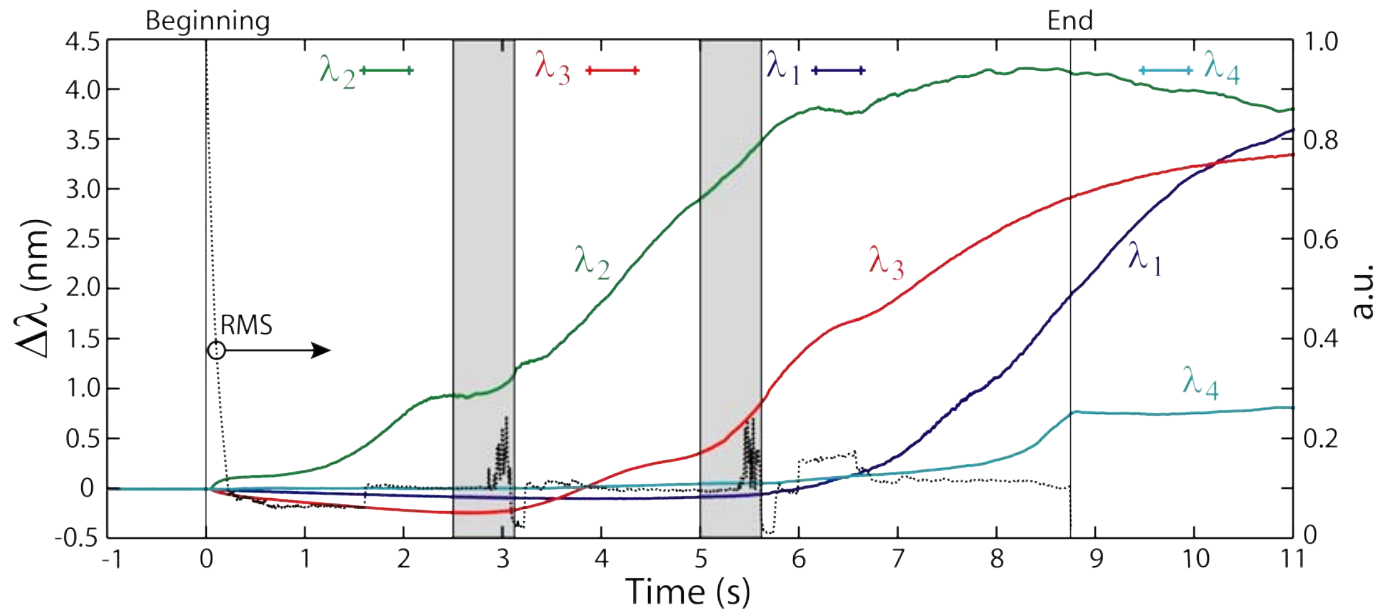

Figure 3. Data from the FBGs are depicted against the welding time (solid lines). The plasma-RMS signal is also shown (dotted line). The equivalents FBG position and weld limits are also plotted over the time scale.

In comparison to the previous results, the achieved temperature drift of this weld (Fig. 3) is slightly higher than in the previous test. This can be observed in the lambda drift of the $\lambda_{2}$ FBG $\left(\Delta \lambda_{2_{A}} \approx 3 \mathrm{~nm}\right.$ vs. $\left.\Delta \lambda_{2_{B}} \approx 4 \mathrm{~nm}\right)$. In addition, the two support gas shortages $\left(T_{1} \approx 3 \mathrm{sec}\right.$ and $\left.T_{2} \approx 5 \mathrm{sec}\right)$ still can be easily identifiable by the RMS signal, although the lack of vibration in this experiment (the two plates are already welded and it can be considered as a bead-on-plate test) makes this detection more difficult. Just by analyzing the FBGs signals, there is no vibration to be recognized; however, the support gas interruption provokes also a power drop in the welding process that can be noticed in the thermal slope of the closest heated FBG: $\lambda_{2}$ for the first shortage and $\lambda_{3}$ for the second. In this pass, the stress release of the weld ending can be also identifiable in the $\lambda_{4}$ FBG signal.

\section{CONCLUSIONS}

FBGs have been used, for the first time to our knowledge, to perform an on-line detection of defects during arc-welding processes. Although FBGs have been used by other authors to study some parameters related to 
the welding process, like the appearance of residual stresses, for instance; we have used the FBGs response to both strain and temperature to study their evolution as weld flaws appear in the process. Two different defects have been provoked to analyze the FBGs response, showing that a drop in the welding current generates a subtle change in the FBGs signal slope. On the other hand, protection gas shortages can be more easily detected as they give rise to noticeable vibrations of the plates. These results have been compared with the plasma-RMS profile obtained by processing the plasma spectra, and the welding test has been repeated for a bead-on-plate scenario, where, as expected, the resulting vibrations are more difficult to be observed. Further works will be focused on the analysis of a wide set of weld flaws and on the employment of an interrogation unit allowing higher frequencies.

\section{ACKNOWLEDGEMENTS}

This work has been supported by the project TEC2010-20224-C02-02 and grant AP2009-1403. Authors would also like to thank Roberto Perez Sierra for his valuable help during the FBGs fabrication process.

\section{REFERENCES}

[1] Sforza, P. and Blasiis, D. d., "On-line optical monitoring system for arc welding," NDT E. Int. 35, 3743 (2002).

[2] Ancona, A., Spagnolo, V., Lugara, P., and Ferrara, M., "Optical sensor for real-time monitoring of co2 laser welding process," Appl. Opt. 40, 6019-25 (2001).

[3] Wikle III, H., Kottilingam, S., Zee, R., and Chin, B., "Infrared sensing techniques for penetration depth control of the submerged arc welding process," Journal of Materials Processing Technology 113, 228-33 (2001).

[4] Zhang, G., Yan, Z., and Wu, L., "Visual sensing of weld pool in variable polarity tig welding of aluminium alloy," Trans. Nonferrous Met. Soc. China (English Edition) 16(3), 522-526 (2006).

[5] Gu, H. and Duley, W., "Statistical approach to acoustic monitoring of laser welding," J Phys D 29, 556-60 (1996).

[6] Mirapeix, J., Garcia-Allende, P., Cobo, A., Conde, O., and Lopez-Higuera, J., "Real-time arc-welding defect detection and classification with principal component analysis and artificial neural networks," NDT E International 40(4), 315-23 (2007).

[7] Naso, D., Turchiano, B., and Pantaleo, P., "A fuzzy-logic based optical sensor for online weld defectdetection," IEEE Transactions on Industrial Informatics 1(4), 259-73 (2005).

[8] Garcia-Allende, P., Mirapeix, J., Conde, O., Cobo, A., and Lopez-Higuera, J., "Arc-welding spectroscopic monitoring based on feature selection and neural networks," Sensors (Basel) 8, 6496-6506 (2008).

[9] Mirapeix, J., Cobo, A., Gonzalez, D., and Lopez-Higuera, J., "Plasma spectroscopy analysis technique based on optimization algorithms and spectral synthesis," Opt. Express 15, 1884-97 (2007).

[10] Lpez-Higuera, J. M., [Handbook of optical fibre sensing technology], Wiley New York, NY, USA: (2002).

[11] Surez, J., Remartnez, B., Menndez, J., Gemes, A., and Molleda, F., "Optical fibre sensors for monitoring of welding residual stresses," Journal of materials processing technology 143, 316-320 (2003).

[12] Moreira, P. M., Frazo, O., Tavares, S. M., de Figueiredo, M. A., Restivo, M. T., Santos, J. L., and de Castro, P. M., "Temperature field acquisition during gas metal arc welding using thermocouples, thermography and fibre bragg grating sensors," Measurement Science and Technology 18(3), 877 (2007).

[13] Richter-Trummer, V., Silva, S., Peixoto, D., Frazo, O., Moreira, P., Santos, J., and De Castro, P., "Fibre bragg grating sensors for monitoring the metal inert gas and friction stir welding processes," Measurement Science and Technology 21(8), 085105 (2010).

[14] Cobo, A., Mirapeix, J., Linares, F., Piney, J., Solana, D., and Lopez-Higuera, J., "Spectroscopic sensor system for quality assurance of the tube-to-tubesheet welding process in nuclear steam generators," IEEE Sensors Journal 7(9), 1219-1224 (2007).

[15] Mirapeix, J., Cobo, A., Fuentes, J., Davila, M., Etayo, J. M., and Lopez-Higuera, J., "Use of the plasma spectrum rms signal for arc-welding diagnostics," Sensors (Basel) 9(7), v (2009). 